International Journal of

Emerging Multidisciplinary Research

\title{
Comparative Study of Young Consumers' Luxury Brand Attachments in Metropolises of Korea and China
}

\author{
Guangdong $\mathrm{Yu}^{1}$, Chang $\mathrm{Liu}^{2}$ and Jingwen $\mathrm{Niu}^{3}$ \\ ${ }^{1-3}$ Professor at Taishan University, China
}

\begin{abstract}
Background/Objectives: In this paper, a new insight is provided into analysis of Chinese and Korean luxury consumption by reflecting the difference between Chinese and Korean customers by using Structural Equation Model (SEM) and fsQCA models. Methods/Statistical analysis: Firstly, exploratory factor analysis, reliability analysis, confirmatory factor analysis, and correlation analysis are computed by the SPSS, Secondly, the path analysis was computed by SAS 9.3. Findings: The findings support the function theory of customers' beliefs showing that Self-monitoring and Mianzi have positive impacts on the Self-presentation attitude. Selfpresentation attitude have a positive impact on the luxury brand attachments. This study also compares estimated results between Korean and Chinese consumers. The findings show that the sense of Mianzi has a stronger impact of sense of Mianzi than Korea customers with respect to self-presentation attitude. Self-monitoring has stronger impacts on Korean customers than Chinese with respect to Self-presentation attitude. Mianzi has stronger impacts on Chinese customers than Korean customers with respect to luxury brand attachments. Improvements/Applications: Self-presentation attitude has stronger impacts on Korean customers than Chinese customers with respect to luxury brand attachments. The impact of Self-presentation attitude with respect to luxury brand attachments in Korean customers is weaker than Chinese customers.
\end{abstract}

\section{Index Terms}

Self-monitoring, Mianzi, Self-presentation attitude, Luxury brand attachments

\author{
Corresponding author : Guangdong Yu \\ 15253809809@163.com \\ - Manuscript received March 29, 2019. \\ - Revised April 30, 2019 ; Accepted June 20, 2019. \\ - Date of publication June 30, 2019. \\ (C) The Academic Society of Convergence Science Inc. \\ 2546-1583 @ 2017 IJEMR. Personal use is permitted, but republication/redistribution requires IJEMR permission.
}




\section{INTRODUCTION}

With the rapid economic globalization, crossborder transactions are booming in every field. Luxury products, originating from Europe, a relatively new and particular commodity, different from ordinary goods, have started to expand its business to the whole world. Asia now has been the third largest market of luxury brands consumption. And as a developing country, China has become the fourth largest luxury market in the world.

The luxury goods' consumption, according to Goldman Sachs, is expected to rise to $29 \%$ in 2015 from $12 \%$ in 2007. Many luxury goods manufacturers also expect that China's growing luxury goods population can help boost their declining sales in other countries, owing to the economic recession. By 2015, China's nominal GDP had been 10.42 trillion US dollars. China's GDP per capita had been also 8200 US dollars. China's relatively strong economic growth will increase luxury sales levels.

The number of middle class has reached 109 million by Thomson Reuters, this will create huge consumption ability. From the data of Bian \& company in 2013, the sales of luxury goods were about 21 billion dollars in China. As the economy grows, the consumption of luxury goods will continue to rise. And as one of New Industrial Economies, Korea has the large luxury market and consumption potential because of relatively higher income and lower sale price. By 2015, Korea's nominal GDP had been 1.37 trillion US dollars. Korea's GDP per capita had been also 27,000 US dollars. The number of middle class has reached 35 million by Thomson Reuters. And according to data of Bian \& company in 2013, the sales of luxury goods was 11 billion dollars in Korea, which puts Korea as the eighth highest country in the luxury market. Though the luxury goods market is expanding, luxury consumers' behaviors are relatively immature research area.

A product with a noticeable brand image stands out in the marketplace. Brand recognition provides a competitive edge to the brand manager and plays a significant role in the consumers' purchasing and luxury brand attachments. A brand signifies quality, status, and personality to the users and viewers [1]. After the consumers purchase the luxury goods, the luxury brand attachments and attitudes (similar to consumers' loyalty toward the luxury brand) will be slowly forming emotional investment by good experience.

Many previous researchers assume that dominant psychological motives of different people are different, and the differences of individual's characteristic can affect their attitudes' functions. According to study of Snyder and DeBono (1985), through forecasting self-monitoring of individual characteristics [2], social functions of consumers' attitude depending on individuals' personal or public identity motives can be revealed. In series of studies, they find the social functions differences of consumers' attitude by comparing the low versus high self-monitoring.

Therefore, the functions that individuals' attitude show can be predicted through consumers' characteristics. Snyder (1974) suggests that Selfmonitoring was a personality trait or ability to regulate behavior to adapt to the development of social situations [3]. People generally showed themselves in different ways and expected to engage in expressive controls [4]. It is also shown that selfmonitoring predicted an attitude of individual selfpresentation [2].

Furthermore, Qin (2010) finds that there was a positive impact between self-monitoring and selfpresentation attitude [5]. Some researches on Mianzi deal with one's morality, reputation, and social status $[6,7]$. These factors are criteria that people used to evaluate one's personal quality. Specially, they maybe use the tactics of self-presentation in order to save their own Mianzi and their vanity [8].

Tsang et al. (2013) also find that the higher the senses of Mianzi, the more frequent the use of selfpresentation [9]. Previous research has shown that consumption of luxury brands was largely determined by the self-presentation attitude, as consumers showed their awareness of individuality. The social status from luxury brands [10], the self-presentation attitude maybe influences the luxury brand attachments. And brand attachment is deemed to be an emotional bond between consumers and brands, or an essential foundation to successful brand management $[11,12]$.

Bruno(2013) present that the luxury brand attachments could be developed between the consumer and the luxury brand [13]. In order to build a good relationships with consumers, brand makers attempt to create strong brand loyalty among their consumers.

A good loyalty means that a brand attachments are stronger. It has been suggested that good emotional attachment with consumers plays a key role in developing brand repurchasing or loyalty in marketing world. Emotional brand attachment is an emotion-laden, target-specific bond between a consumer and a brand [12].

In the previous studies using SEM, the relationship between cultural identity and attitude has been found between similar cultures and different cultures. Wilcox et al. (2009) examine the relationships among the individual needs, selfmonitoring [10], affective attitude, and purchasing intention for luxury brands in eastern and western cultures. According to consumer behaviors among the USA, Korea and China, Dana et al. (2016) report the similarities and differences of consumer motivations 
to interact on brand websites in the international marketplace [14].

They develop the relationships among the brand engagement self-concept, consumer interactions on brand websites, identification with brand websites as communities, materialism and social normative influence. They find that respondents who view brands as integral parts of self-concept also interact more on brand websites. Susceptibility to social normative influence and a positive attitude toward materialism are important predictors of consumer interactions in all countries.

Overall, their article finds stronger cross-national similarities than differences. Qin(2010) examines the relationships between the social functional attitudes and affective attitudes on consumers' purchasing intentions in eastern and western cultures [5]. The collectivism culture is similar between Korea and China, but Korean young people have more collectivist attitude in comparison to Chinese (Kondo, Toshio).

Whether the similarity or difference across different nations, who plays a key role depends on the samples or factors you choose. Considering these, we also find few studies have empirically compared to the difference of consumption between Korea and China. It is necessary to analyze whether consumers' motivations to luxury brand attachments differ between the two countries, and how accounts for those differences. Despite the growing demand for luxury brands between Korea and China, to better show the differences between Korean and Chinese consumers, this paper investigates four variables, which are Self-monitoring, Self-presentation attitude, Mianzi and Luxury brand attachments.

SEM combines and extends factor analysis and multiple regression analysis (MRA). SEM and MRA are symmetric tests that report on the "net effects" of variables on a dependent variable with a set of independent variables. Many previous studies found the relationships between luxury goods and related variables by using SEM models. Gigerenzer (1991) emphasizes how method selections affects theory perspectives. Pei-LingWu (2014) presents key propositions in complexity theory:

(1) no single antecedent condition is a sufficient or necessary indicator of a high score in an outcome condition; (2) a few of many available complex configurations of antecedent conditions are sufficient indicators of high scores in an outcome condition; (3) contrarian cases occur, that is, low scores in a single antecedent condition associates with both high and low scores for an outcome condition for different cases.

(2) It is necessary to use fsQCA model to research the relationships between luxury goods and related variables. In this paper, the fsQCA is also used to analyze the relationships among the four variables.

(3) But the fsQCA describes how a use of Boolean algebra and asymmetric analytics provides a new angle, presents its findings compared with SEM.

The purpose of our study offers a new and different understanding on luxury brands attachments between Korea and China by examining how consumers' personal characteristics are among the three factors: Self-monitoring, Mianzi and Selfpresentation attitude. The main contributions of this work are: ( $i$ ) suggesting the effect of Selfmonitoring and Mianzi to both Self-presentation attitude and Luxury brand attachments in Korean and Chinese consumers respectively and comparing the differences of effects between Korean and Chinese consumers respectively; (ii) suggesting the effect of Self-presentation attitude to Luxury brand attachments in Korean and Chinese consumers and comparing the differences of effects between Korean and Chinese consumers? According to these results, marketing strategies may be distinct difference in Korea and China luxury markets.

In section two, the theoretical background is explained. In section three, the research and hypotheses are structured. In section four, the results of the model are analyzed and hypotheses are tested. In section five, conclusions are presented.

\section{THEORETICAL BACKGROUND OF VARIABLES}

\section{A. Self-monitoring}

Snyder (1974) finds that Self-monitoring is a personality construction by showing individual differences in self-presentation; is defined to control an individual's behaviors [3]. Generally, selfmonitoring is defined in two ways: First, the degree which people could regulate their response to others people in social situations. Second, the extent which people are sensitive to social context cues $[15,16]$.

It is a trait that refers to an ability to regulate behavior to accommodate social situations. People concerned with their expressive self-presentation tend to closely monitor their audience in order to ensure appropriate or desired public appearances.

However, the concept of self-monitoring is always argumentative from two aspects. Within personality research there is the tension between traits and situations. Are people more inclined to behave consistent with their personality traits or are they influenced by the immediate social situation? 


\section{B. Mianzi}

On the physical level, Mianzi means the physical face. On the connotative level, Mianzi means that people can obtain a kind of prestige or reputation through their success and ostentation; Mianzi is accumulated little by little depending on personal effort or intelligent control. Mianzi is also a recognition ego of people depending on the external environment [17].

Mianzi is an important factor within Chinese social settings and in a business context. Yuanxin, Gao (2014) suggests that the culture leaded to Mianzi consciousness and the Mianzi conception leaded to particular Chinese consumer behavior (Yuanxin, Gao, 2014).

Jinfeng Wang (2013) states people were likely to purchase luxury goods to make themselves and their sociality counterparts have face [18], because they thought expensive luxury goods were the symbol of wealth and success. Cho (2015) find that shame consciousness and consciousness for others among face senses were significantly relationship with the choice of a logo size of luxury goods in Korea [19].

\section{Self-presentation attitude}

Self-presentation is behavior that attempt to convey some information about oneself or some image of oneself to other people. It denotes a class of motivations in human behavior. These motivations are in part stable disposition of individuals but they depend on situational factors to elicit them. Specially, self-presentational motivations are activated by the evaluative presence of other people and by others' knowledge of one's behavior.

Two types of self-presentational motivations can be distinguished. One is to match one's selfpresentation to the audience's expectations and preferences. The other is to match one's selfpresentation to one's own ideal self. Based on this, many researchers take some steps further. The need for self-presentation, according to Leary \& Kowalski (1990), is described as below: it is the process in which individuals attempt to control the social impressions to other people [20].

Because the impressions people made on other people existed implications for how others perceived, evaluated, and treated them, people often showed themselves in different ways that would create certain impressions in other people eyes. In this paper, we have draught on the functional theory of attitude from Katz (1960) and Shavitt (1989), which suggest that attitudes have contributed to important valueexpressive functions similar to facilitating selfpresentation [21,22].

Therefore, a self-presentation attitude toward luxury brands can be defined as predisposition to show social image using the luxury brands; can also be defined as an orientation so as to display individual identity and underlying values using the luxury brands $[10,22]$ and communicated central beliefs with someone $[10,21]$

\section{Luxury Brand}

As unnecessary Luxury brands are commonly associated with "indulgence of the senses, regardless of price" [23]. Although luxury brands possess the traits of premium quality, high ratio of value, recognizable style, uniqueness, and global reputation [23], consumers would like to purchase luxury brands primarily for symbolic reasons to reflect their status and social goals [10]. Bronu, Godey, ET (2013) also find the causal model of relationships between decision-making and luxury brand attachments[13].

\section{E. Luxury Brand Attachments}

Generally, Brand attachment is an emotionally charged bonding between consumers and brands, and essential foundation to successful brand management [11,12]. Establishing emotional bond between consumers and brands is an objective of companies, as strong bond maybe lead to positive outcomes, such as loyalty and obtaining a price premium $[12,24,25]$.

Recognizing the importance of creating consumers' attachment specifically within the brand management literature, many scholars have continued to study the formed process of brand attachments and its measurement.

Considering to the brand attachment's importance, previous research had conducted by Thomson and colleagues (2005) suggest that emotional brand attachments reflect the bond between a consumer and a specific brand, while the bond itself involve feelings toward the brand.

Subsequently, brand attachment has been expanded to include the emotional bond and the cognitive bond by Park et al (2006) [26]. Based on similar study, Park and colleagues (2010) also propose that brand attachment as the power of the bond is linked the self to the brand.

Other researchers extend brand attachment as more than emotions toward the brand and propose that brand attachment is reflected by mental representations that involve rich cognitive schemata including brand-self cognitions, thoughts, and autobiographical brand memories [25].

Therefore, Brand-self connection and brand prominence occur as two critical factors that reflected the conceptual properties of brand attachments. If consumers often purchase the luxury brand, the luxury brand attachments will be formed. 


\section{RESEARCH MODEL AND HYPOTHESES}

There are two method to build up the models. First, SEM are often used to assess unobservable latent variables. They often invokes a measurement model which defines a latent variable using one or more observed variables, and a structural model that imputes relationships between latent variables.

The links between constructs of a structural equation model may be estimated with independent regression equations or through more involved approaches such as those employed in LISREL or SAS.

Use of SEM is commonly justified in the social sciences because of its ability to impute relationship between unobserved constructs from observed variables. Second, the fuzzy truth table algorithm is used to construct the crisp truth tables in the fsQCA. Many available configurations of antecedent conditions are sufficient or necessary indicators of high scores in an outcome condition.

\section{A. Self-monitoring, Self-presentation attitude and Luxury brand attachment}

Snyder also found that Self-monitoring is a sense which indicated what Self-presentation was appropriate or not in a certain situation in 1974. Because consumers' personal traits shape their attitudes [21,22], generally consumers' selfmonitoring maybe affect their self-presentation attitude toward luxury brands. Consumers would like to show their success and prestige, to help them enter into certain social situations or reference groups, and to make other people pay attention through their luxury brands [10].

From Snyder (1974), an individual who is high in Self-Monitoring concerned about social appropriateness in order to monitor his/her own nonverbal presentation such as dress and appearance. These high self-monitoring individuals are very sensitive to social images and can make their behaviors to satisfy social norms [27].

Hyejoo Lee and Ho Jung Choo (2013) argue that the self-monitoring has positive influence on the selfpresentation attitude using Korean sample. Qin, Bian (2010) also indicates that the self-monitoring has a positive effect on self-presentation attitude by comparing American and Chinese students.

In this study, consumers' self-monitoring was expected to be positive relationship with their selfpresentation attitude, as luxury brand consumers desired to bolster their social image though showing upscale and unique status.

Despite Korea and China have collectivist culture, this culture is stronger in Korea than in China [28]. Considering the difference between Chinese and
Korean customers, the following hypotheses (Figure 1) are offered:

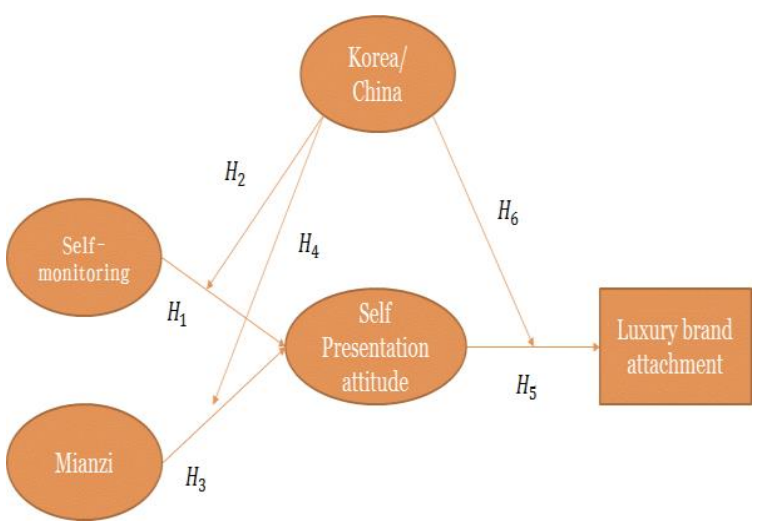

Fig. 1. Research Model

H1: Self-monitoring has a positive effect on selfpresentation attitude.

H2 : The impact of Self-monitoring toward selfpresentation attitude should be stronger on Korean customers than Chinese ones.

H7: Self-monitoring has a positive effect on Luxury brand attachments.

H8: The impact of Self-monitoring toward Luxury brand attachments should be stronger on Korean customers than Chinese ones.

\section{B. Mianzi, Self-Presentation attitude and Luxury} brand attachment

Xiao, G (2005) finds that Chinese consumers wished to exhibit their achievement by using foreign luxury goods. This would make they feel immediate social acceptance and Mianzi up to high social status. Simons (2006) suggests that consumers took the luxury goods as a symbol of their high social status in a nation that had long tradition of saving Mianzi or face [29]. Warveni, Jap (2010) reveals that Mianzi does influence Chinese consumer values in the quest of social prestige.

Myungsun Chung and Hyejin Kim (2009) state that sensitivity of Mianzi (face) also influence purchasing preference of Korean consumers [30]. Seungho Cho and Sanghoon Cho (2015) state that the higher sense of Mianzi is, the more intention of purchasing luxury goods is in Korean consumers. Except for this, Tsang et al. (2013) find that the higher the sense of Mianzi [9], the more frequent the use of the ingratiation tactics of other enhancement, conformity, and selfpresentation.

Swaminathan et al. (2007) argue that brands can strengthen consumer identities by serving selfpresentation goals [31], and thus consumers took the luxury brand as a tool to represent their Mianzi. And some Chinese people have found a new creative way to save face. For example, some people who could 
not afford top-brand products would be buying expensive bags with luxury brand names or logos to gratify their vanity.

And Hyejoo Lee (2013) finds that Korean consumers vanity also have positive affect on selfpresentation attitude toward luxury brands [32]. Mianzi maybe influence the self-presentation attitude of consumers as the vanity. Considering the difference between Chinese and Korean culture, the following hypotheses (Figure 1) are offered:

H3: The sense of Mianzi has a positive effect on self-presentation attitude.

H4: The impact of Mianzi toward self-presentation attitude should be stronger on Chinese customers than Korean ones.

H9: The sense of Mianzi has a positive effect on Luxury brand attachments.

H10: The impact of Mianzi toward luxury brand attachments should be stronger on Chinese customers than Korean ones.

\section{Self-presentation attitude and luxury Brand Attachments}

High Self-presentation's consumers prefer to consume luxury brands for their image-related reasons (Shavitt\& Lowrey, \& Han, 1992; Wilcox et al., 2009). Because luxury brands include some factors such as prestige, high social hierarchy etc. $[23,33]$, they extremely satisfy the vanity of consumers who have strong self-presentation attitudes to their image.

It is reasonable that consumers' attitude of selfpresentation with a focal brand maybe fostered emotional attachments to the brand. This is because feelings of being emotionally attached to a brand can be developed based on an individual's recognition of commonalities between the self-presentation and the brand.

If consumers like the luxury brands, user identities shared by a luxury brand could promote a consumer's feeling of connection with the brand, brought some emotional attachments to the luxury brand. Hayjoo, Lee (2013) reveals that the self-presentation attitude of Korean consumers has a positive influence on luxury brand purchase intention through an affective attitude.

Bruno(2013) argues that the luxury brand attachment is driven primarily through the development of the affection. Qin(2010) finds that the Self-presentation attitude has much stronger impact on purchase intention of luxury brand among Chinese consumers than U.S. consumers.

It is possible that self-presentation attitude will have an effect on luxury brand attachments with respect to the difference between Chinese and Korean customers, the following hypotheses (Figure 1) are offered:

H5: The self-presentation attitude has a positive impact toward luxury brand attachments.

H6: The impact of self-presentation attitude toward luxury brand attachments will be stronger on Korean customers than Chinese ones.

\section{DATA ANALYSIS AND RESUlts}

\section{A. Data Collection}

This paper adopts a questionnaires survey to collect the data. The target population to data collection consist of the Chinese people who are living in big cities (Beijing, Shang) and Korean people who are living in big cities such as Seoul, Pusan. The questionnaires survey targeted the Korean and Chinese Young people. Survey questionnaire is shown in Appendix A.

Data collection is collected from Aug. 24, 2015 to Nov. 30, 2014. In table 1, a total of 607 questionnaires are returned including 288 from Korean sample and 295 from Chinese sample. 583 valid questionnaires are used for the data analysis.

Table 1. SAmple Statistics

\begin{tabular}{|c|c|c|c|}
\hline Items & Questions & Frequency & Ratios \\
\hline \multirow{2}{*}{ Nationality } & Korea & 288 & $49.4 \%$ \\
\hline & China & 295 & $50.6 \%$ \\
\hline \multirow{2}{*}{ Gender } & Male & 276 & $47.3 \%$ \\
\hline & Female & 307 & $52.7 \%$ \\
\hline \multirow{2}{*}{ Age } & 20 29 & 203 & $33.94 \%$ \\
\hline & 30 39 & 383 & $66.06 \%$ \\
\hline \multirow{5}{*}{ Job } & Student & 117 & $20.2 \%$ \\
\hline & Employee & 311 & $53.3 \%$ \\
\hline & Civil Servant & 80 & $13.7 \%$ \\
\hline & Private Owners & 69 & $11.8 \%$ \\
\hline & Others & 6 & $1 \%$ \\
\hline \multirow{4}{*}{$\begin{array}{lr}\text { Frequency } & \text { of } \\
\text { Shopping } & \text { Per } \\
\text { Month } & \end{array}$} & 1 2 time(s) & 154 & $26.4 \%$ \\
\hline & $3 \sim 4$ times & 278 & $47.7 \%$ \\
\hline & $\begin{array}{|ll|}\begin{array}{l}\text { More than } 5 \\
\text { times }\end{array} & \\
\end{array}$ & 144 & $24.7 \%$ \\
\hline & Others & 7 & $1.2 \%$ \\
\hline \multirow{2}{*}{$\begin{array}{l}\text { Korean won for } \\
\text { Shopping Per } \\
\text { Month }\end{array}$} & $\begin{array}{l}1000,000 \sim 2,00 \\
0,000\end{array}$ & 203 & $34.8 \%$ \\
\hline & $\begin{array}{l}2,000,000- \\
5,000,000\end{array}$ & 380 & $65.2 \%$ \\
\hline
\end{tabular}




\section{B. Model Assessment}

In this paper, the collected data is inputted in the SPSS 19.0 program and SAS 9.3 Calis to test the hypotheses, respectively; Firstly, exploratory factor analysis, reliability analysis, confirmatory factor analysis, and correlation analysis are computed by the SPSS, Secondly, the path analysis was computed by SAS 9.3. All constructs are measured by a 7-point Likert type scale (1=strongly disagree to $7=$ strongly agree). And finally, 25 items are chosen to measure the respondents' perceptions.

\section{B.1 Exploratory Factor Analysis}

Exploratory factor analysis (EFA) can be used as a tool to determine the number of latent variables and the underlying factor structure of variables before a more in-depth analysis. It is conducted to test whether items are loaded on the appropriate factors as expected.

Generally, variables which factor loadings are greater than 0.4 should be considered significant and used in defining the factor [34]. If the loadings are greater than 0.5 , it should be more important variables. However, in social science, the loadings that more than 0.6 are used frequently. In this paper, the factor loadings which are more than 0.6 are chosen.

The exploratory factor analysis for all variables is computed; and the Kaiser-Meyer-Olkin (KMO) reaches 0.83 , which means that the data are suitable to exploratory factor analysis. In order to achieve a high level of reliability, the items with factors loading lower than 0.6 are abandoned, there are five dimensions in self-monitoring, four dimensions in self-presentation attitudes, three dimensions in Mianzi and luxury brand attachments, respectively. The results of exploratory factor analysis are shown in Table 2.

Table 2. ANALYSIS OF FACTOR LOADING

\begin{tabular}{|c|c|c|c|c|}
\hline Variable & Items & $\begin{array}{l}\text { Factor } \\
\text { Loading } \\
\text { ( China ) }\end{array}$ & $\begin{array}{l}\text { Factor } \\
\text { Loading } \\
\text { ( Korea } \\
\text { ) }\end{array}$ & $\begin{array}{l}\text { Factor } \\
\text { Loading } \\
\text { Both }\end{array}$ \\
\hline \multirow{5}{*}{$\begin{array}{l}\text { Self- } \\
\text { monitorin } \\
g\end{array}$} & $\begin{array}{l}\text { self-monitoring- } \\
1\end{array}$ & 0.839 & 0.754 & 0.824 \\
\hline & $\begin{array}{l}\text { self-monitoring- } \\
2\end{array}$ & 0.832 & 0.748 & 0.771 \\
\hline & $\begin{array}{l}\text { self-monitoring- } \\
7\end{array}$ & 0.848 & 0.789 & 0.823 \\
\hline & $\begin{array}{l}\text { self-monitoring- } \\
8\end{array}$ & 0.801 & 0.967 & 0.770 \\
\hline & $\begin{array}{l}\text { self-monitoring- } \\
9\end{array}$ & 0.79 & 0.812 & 0.744 \\
\hline \multirow{2}{*}{$\begin{array}{l}\text { Self- } \\
\text { presentatio }\end{array}$} & $\begin{array}{l}\text { self- } \\
\text { presentation-1 }\end{array}$ & 0.807 & 0.831 & 0.782 \\
\hline & self- & 0.915 & 0.819 & 0.758 \\
\hline
\end{tabular}

\begin{tabular}{|c|l|l|l|l|}
\hline \multirow{4}{*}{ attitude } & presentation-2 & & & \\
\cline { 2 - 5 } & $\begin{array}{l}\text { self- } \\
\text { presentation-3 }\end{array}$ & 0.896 & 0.833 & 0.792 \\
\cline { 2 - 5 } & $\begin{array}{l}\text { self- } \\
\text { presentation-5 }\end{array}$ & 0.871 & 0.867 & 0.789 \\
\hline \multirow{2}{*}{$\begin{array}{l}\text { Luxury } \\
\text { brand } \\
\text { attachment } \\
\text { s }\end{array}$} & $\begin{array}{l}\text { brand } \\
\text { attachment-2 }\end{array}$ & 0.951 & 0.823 & 0.792 \\
\cline { 2 - 5 } & $\begin{array}{l}\text { brand } \\
\text { attachment-3 }\end{array}$ & 0.909 & 0.879 & 0.865 \\
\cline { 2 - 5 } & $\begin{array}{l}\text { brand } \\
\text { attachment-4 }\end{array}$ & 0.968 & 0.822 & 0.827 \\
\hline \multirow{2}{*}{ Mian zi } & mian zi-2 & 0.888 & 0.834 & 0.789 \\
\cline { 2 - 5 } & mian zi-3 & 0.892 & 0.885 & 0.849 \\
\cline { 2 - 5 } & mian zi-4 & 0.856 & 0.941 & 0.827 \\
\hline
\end{tabular}

\section{B.2 Reliability Analysis and Convergent Validity} Analysis

Reliability is closely connected with the quality of measurement, and it is estimated by calculating Cornbrash's Alpha, which is a measure of internal consistency in each measured scale. Nunnally (1978) recommended that Cornbrash's Alpha of a scale should be greater than 0.7 for items to be used together as a construct. As shown in Table 3-1, 3-2, 3-3, all Cornbrash's Alpha values are more than 0.7, this means all the factors have good internal consistency and reliability.

Convergent validity is used to examine the degree to which a measurement item is connected with other items that measure the same construct. It is estimated by composite reliability (CR) and average variance extracted (AVE). All factors should have the composite reliability (CR) value equal to or above 0.70 , and average variance extracted (AVE) should higher than 0.50 .

Table 3-1. Result of Reliability and Convergent VALIDITY ANALYSIS

\begin{tabular}{|l|l|l|l|l|l|}
\hline Construct & $\begin{array}{l}\text { Initial } \\
\text { Numbers } \\
\text { of Items }\end{array}$ & $\begin{array}{l}\text { Final } \\
\text { Numbers of } \\
\text { Items }\end{array}$ & $\begin{array}{l}\text { Cronbach } \\
\text { Alpha }\end{array}$ & AVE & CR \\
\hline Self-monitoring & 9 & 5 & 0.761 & 0.7019 & 0.9005 \\
\hline Mian zi & 4 & 3 & 0.878 & 0.6865 & 0.8677 \\
\hline $\begin{array}{l}\text { Self- } \\
\text { presentation } \\
\text { attitude }\end{array}$ & 6 & 4 & 0.902 & 0.6174 & 0.8658 \\
\hline $\begin{array}{l}\text { Luxury Brand } \\
\text { Attachments }\end{array}$ & 4 & 3 & 0.798 & 0.6865 & 0.862 \\
\hline
\end{tabular}

Table 3-2. Result of Reliability and Convergent VALIDITY ANALYSIS ABOUT CHINA

\begin{tabular}{|l|l|l|l|l|l|}
\hline Construct & $\begin{array}{l}\text { Initial } \\
\text { Numbers of } \\
\text { Items }\end{array}$ & $\begin{array}{l}\text { Final } \\
\text { Numbers } \\
\text { of Items }\end{array}$ & $\begin{array}{l}\text { Cronbach } \\
\text { Alpha }\end{array}$ & AVE & CR \\
\hline Self-monitoring & 9 & 5 & 0.906 & 0.6141 & 0.9272 \\
\hline
\end{tabular}




\begin{tabular}{|l|l|l|l|l|l|}
\hline $\begin{array}{l}\text { Self-presentation } \\
\text { attitude }\end{array}$ & 6 & 4 & 0.883 & 0.6536 & 0.9182 \\
\hline $\begin{array}{l}\text { Luxury brand } \\
\text { attachments }\end{array}$ & 6 & 3 & 0.772 & 0.6028 & 0.8576 \\
\hline Mianzi & 4 & 3 & 0.9 & 0.7704 & 0.9306 \\
\hline
\end{tabular}

Table 3-3. Result of Reliability and Convergent VALIDITY ANALYSIS ABOUT KOREA

\begin{tabular}{|l|l|l|l|l|l|}
\hline Construct & $\begin{array}{l}\text { Initial } \\
\text { Numbers } \\
\text { of Items }\end{array}$ & $\begin{array}{l}\text { Final } \\
\text { Numbers } \\
\text { of Items }\end{array}$ & $\begin{array}{l}\text { Cronb } \\
\text { ach } \\
\text { Alpha }\end{array}$ & AVE & CR \\
\hline $\begin{array}{l}\text { Self- } \\
\text { monitoring }\end{array}$ & 9 & 5 & 0.741 & 0.6148 & 0.9266 \\
\hline $\begin{array}{l}\text { Self- } \\
\text { presentation } \\
\text { attitude }\end{array}$ & 6 & 4 & 0.858 & 0.6575 & 0.9197 \\
\hline $\begin{array}{l}\text { Luxury brand } \\
\text { attachments }\end{array}$ & 6 & 3 & 0.852 & 0.621 & 0.9066 \\
\hline Mianzi & 4 & 3 & 0.688 & 0.7903 & 0.9185 \\
\hline
\end{tabular}

As shown in Table3-1, 2, 3, all of the composite reliability (CR) and average variance extracted (AVE) values exceed the acceptable level of 0.7 and 0.5 , which means the measurement items for research constructs have convergent validity.

\section{B.3 Structural equation modeling (SEM) Analysis}

Generally, the structural model is constructed to examine the hypothesized relationships among factors structure. There are seven common model-fit measures used to assess the model's overall goodness-of-fit: the ratio of $\chi 2$ to degrees-of-freedom (DF), the value of 5 or smaller is desirable ; goodness-of-fit index (GFI), the value of 0.9 or higher is desirable; adjusted goodness-of-fit index (AGFI), the value of 0.8 or higher is expected; normalized fit index (NFI), the value of 0.9 or higher is expected; comparative fit index (CFI), the value of 0.9 or higher is expected; $\mathrm{CN}$ and the value of 200 or higher is expected :and root mean square residual (RMR), the value of 0.05 or smaller is expected; Overall fit indices of measurement models are shown in Table 4.

Table 4. Results of Covariance Structure Analysis

\begin{tabular}{|c|c|c|c|c|}
\hline Fit Indices & $\begin{array}{ll}\text { A. } & \text { Reco } \\
\text { mmended } \\
\text { B. } & \text { Value }\end{array}$ & $\begin{array}{ll}\text { C. } & \text { Structu } \\
\text { re } & \\
\text { Model } \\
\text { D. } \\
\text { na) }\end{array}($ Chi & $\begin{array}{ll}\text { E. } & \text { Structu } \\
\text { re } & \text { Model } \\
\text { F. } & \text { (Kore } \\
\text { a) } & \end{array}$ & $\begin{array}{l}\text { G. Struc } \\
\text { ture } \\
\text { Model } \\
\text { H. (Bot } \\
\text { h) }\end{array}$ \\
\hline$\chi^{2} / \mathrm{DF}$ & $\leq 5.00$ & 1.4702 & 0.2212 & 3.7504 \\
\hline
\end{tabular}

\begin{tabular}{|l|l|l|l|l|}
\hline $\begin{array}{l}\text { Goodness- } \\
\text { of-Fit (GFI) }\end{array}$ & $\geq 0.90$ & 0.9783 & 0.9893 & 0.9732 \\
\hline $\begin{array}{l}\text { Adjusted } \\
\text { Goodness- } \\
\text { of-Fit } \\
\text { (AGFI) }\end{array}$ & $\geq 0.80$ & 0.9432 & 0.86 & 0.9509 \\
\hline $\begin{array}{l}\text { Normed Fit } \\
\text { Index (NFI) }\end{array}$ & $\geq 0.90$ & 0.9077 & 0.9975 & 0.9329 \\
\hline $\begin{array}{l}\text { Comparativ } \\
\text { e Fit Index } \\
\text { (CFI) }\end{array}$ & $\geq 0.90$ & 0.9394 & 0.9605 & 0.9928 \\
\hline CN & $\geq 200$ & 295 & 288 & 583 \\
\hline $\begin{array}{l}\text { Root Mean } \\
\text { Square } \\
\text { Residual(R } \\
\text { MR) }\end{array}$ & $\leq 0.05$ & 0.0386 & 0.0081 & 0.0169 \\
\hline
\end{tabular}

\section{B.4 Test of Equation Model}

As shown in Table 4, the results of fit indices with their corresponding recommended values provide the evidence of a good model fit ( $x^{2} / \mathrm{DF}=$ 3.7504, GFI $=0.9732$, AGFI $=0.9509, \mathrm{NFI}=0.9329$, $\mathrm{CFI}=0.9928, \mathrm{CN}=583, \mathrm{RMR}=0.017$ ).

These goodness-of-fit indices for equation model indicate that the research model is acceptable. The similar results could be obtained by comparing fit indices between China and Korea.

\section{B.5 Path Analysis and fuzzy set qualitative} comparative analysis

The path coefficients of these hypotheses (H1, H3, H5) are statistically significant, while the path coefficients of and hypotheses are not statistically significant. The path coefficients of Self-monitoring and Mianzi towards self-presentation attitude and self-presentation attitude towards luxury brand attachments are positive and significant (0.0231, 0.4098 and 0.571 , respectively; $p$ values 0.05 or $0.01)$.

This indicates higher self-monitoring and sense of Mianzi (saving face) can lead to higher sense of Selfpresentation attitude; and higher self-presentation attitude leads to higher brand attachments in terms of Korean and Chinese consumers. From Table 6, lower Mianzi and higher self-monitoring can lead to higher self-presentation attitude in Korea, but lower selfmonitoring can lead to higher self-presentation attitude in China. And whether in Korea or China, higher sense of Mianzi cannot lead to higher selfpresentation attitude. 
Table 5. Structure COEFficient And Results of HYPOTHESES TESTING

\begin{tabular}{|c|c|c|c|c|c|c|}
\hline $\mathrm{H}$ & Hypotheses & $\begin{array}{l}\text { Path } \\
\text { Coefficient } \\
\text { CH } \\
\text { value) }\end{array}$ & $\begin{array}{l}\begin{array}{l}\text { Path } \\
\text { Coefficiert }\end{array} \\
\text { KR } \\
\text { value) }\end{array}$ & $\begin{array}{l}\text { Path } \\
\text { Coefficiert } \\
\begin{array}{l}\text { Bath } \\
\text { value })\end{array}\end{array}$ & $\Delta x^{2}(\mathrm{df})$ & $\begin{array}{l}\text { Accept/ } \\
\text { Reject }\end{array}$ \\
\hline $\mathrm{H} 1$ & SM-SP & & & $\begin{array}{l}0.0231 * \\
(2.5152)\end{array}$ & & A \\
\hline $\mathrm{H} 2$ & $\begin{array}{l}\text { SM--SP } \\
\text { CHN and KR }\end{array}$ & $\begin{array}{l}0.042 \\
(0.782)\end{array}$ & $\begin{array}{l}0.0596 \\
(0.756)\end{array}$ & & $\begin{array}{l}3.67 * * \\
(1)\end{array}$ & A \\
\hline $\mathrm{H} 3$ & MZ--SP & & & $\begin{array}{l}0.4098^{* *} \\
(9.559)\end{array}$ & & A \\
\hline $\mathrm{H} 4$ & $\begin{array}{l}\text { MZ--SP between } \\
\text { CHN and KR }\end{array}$ & $\begin{array}{l}0.5076^{* * *} \\
(9.263)\end{array}$ & $\begin{array}{l}0.2811^{* * *} \\
(3.733)\end{array}$ & & $\begin{array}{l}5.12 * * \\
(1)\end{array}$ & A \\
\hline H5 & SP--BA & & & $\begin{array}{l}0.571^{* * *} \\
(7.821)\end{array}$ & & A \\
\hline H6 & $\begin{array}{l}\text { SP--BA } \\
\text { CHN and KR }\end{array}$ & $\begin{array}{l}0.443^{* * *} \\
(3.459)\end{array}$ & $\begin{array}{l}0.783^{* * *} \\
(7.336)\end{array}$ & & $\begin{array}{l}6.54 * * \\
(1)\end{array}$ & A \\
\hline H7 & MZ-BA & & & $\begin{array}{l}0.232 \\
(1.04)\end{array}$ & & $\mathrm{R}$ \\
\hline $\mathrm{H} 8$ & $\begin{array}{l}\text { MZ-BA between CHN } \\
\text { and KR }\end{array}$ & $\begin{array}{l}0.405 \\
(2.788)\end{array}$ & $\begin{array}{l}0.324 \\
(3.09) \\
\end{array}$ & & $\begin{array}{l}4.21 * * \\
(1)\end{array}$ & A \\
\hline H9 & SM-BA & & & $\begin{array}{l}0.345 \\
(1.65)\end{array}$ & & $\mathrm{R}$ \\
\hline H10 & $\begin{array}{l}\text { SM-BA } \\
\text { between CHN and KR }\end{array}$ & $\begin{array}{l}0.309 \\
(1.76)\end{array}$ & $\begin{array}{l}0.321 \\
(1.901)\end{array}$ & & $\begin{array}{l}1.83 \\
(1)\end{array}$ & $\mathrm{R}$ \\
\hline $\begin{array}{l}\text { Note } \\
\text { SM= } \\
\text { BA=l }\end{array}$ & $\begin{array}{l}* \mathrm{e}<0.05, * * \mathrm{p}<0.01 \mathrm{Cl} \\
=\text { Self-monitoring, } \\
=\text { Luxury brand attachmen }\end{array}$ & $\begin{array}{l}\mathrm{HN}=\text { Chine } \\
\mathrm{Z}=\text { Mianzi, } \\
\text { nts. }\end{array}$ & $\begin{aligned} \text { ese, } & \mathrm{KR}=\mathrm{K} \\
& \mathrm{SP}=\mathrm{S}\end{aligned}$ & $\begin{array}{l}\text { Corean A } \\
\text { elf-pres }\end{array}$ & $\begin{array}{l}\text { ept }=\mathrm{A}, \mathrm{Re} \\
\text { tation }\end{array}$ & $\begin{array}{l}\text { eject }=R \text {. } \\
\text { attitude, }\end{array}$ \\
\hline
\end{tabular}

Table 6. OutCome MOdels With MiAnZI AND SELF-MONI TORING FOR PREDICTING SELF-PRESENTATION ATTITUDE

\begin{tabular}{|l|l|l|l|}
\hline Korea & Raw coverage & $\begin{array}{l}\text { Unique } \\
\text { coverage }\end{array}$ & Consistency \\
\hline $\begin{array}{l}\sim \text { Mianzi*self- } \\
\text { monitoring }\end{array}$ & 0.3361 & 0.3365 & 0.9721 \\
\hline \multicolumn{2}{|l|}{ Solution coverage: 0.3365} & Ronsistency \\
\hline Solution consistency: 0.9223 & $\begin{array}{l}\text { Unique } \\
\text { coverage }\end{array}$ & 0.9086 \\
\hline China & Raw coverage & 0.2011 & \\
\hline$\sim$ self-monitoring & 0.5361 & &
\end{tabular}

\begin{tabular}{|l|}
\hline Solution coverage: 0.5351 \\
\hline Solution consistency: 0.9011 \\
\hline
\end{tabular}

Table 7. OUTCOME MODELS WITH SELF-PRESENTATION ATTI TUDE FOR PREDICTING LUXURY BRAND ATTACHMENTS

\begin{tabular}{|l|l|l|l|}
\hline Korea & Raw coverage & $\begin{array}{l}\text { Unique } \\
\text { coverage }\end{array}$ & Consistency \\
\hline $\begin{array}{l}\text { self-presentation } \\
\text { attitude }\end{array}$ & 0.9196 & 0.0012 & 0.8133 \\
\hline \multicolumn{2}{|l|}{ Solution coverage: 0.7509} & Consistency \\
\hline Solution consistency: 0.8185 & Raw coverage & $\begin{array}{l}\text { Unique } \\
\text { coverage }\end{array}$ & 0.9586 \\
\hline China & 0.0177 & \\
\hline $\begin{array}{l}\text { self-presentation } \\
\text { attitude }\end{array}$ & 0.7898 & \\
\hline Solution coverage: 0.7066 & \\
\hline Solution consistency: 0.9322 & \\
\hline
\end{tabular}

From Table 7, higher self-presentation attitude can lead to higher luxury brand attachments on both Korea and China, the similar results can be found as shown in the Table 5. However, from the path coefficients of $\mathrm{H} 7$ and $\mathrm{H} 9$ hypotheses, it cannot confirm that both Korean and Chinese consumers become more pea cockish (such as saving face) and keep themselves good image more by means of luxury brand attachments after purchasing luxury brands.

According to the results in Table 8, higher sense of Mianzi can lead to higher luxury brand attachments on Chinese consumers, but lower Mianzi can lead to higher luxury brand attachments on Korean consumers. Lower self-monitoring and higher selfpresentation attitude can lead to higher luxury brand attachments for Korea, only higher self-presentation attitude can lead to higher luxury brand attachments for China.

Table 8. Outcome MODEls With MiAnZi, SELF-MONitorin G AND SELF-PRESENTATION ATTITUDE FOR PREDICTING LUX URY BRAND ATTACHMENTS

\begin{tabular}{|l|l|l|l|}
\hline Korea & Raw coverage & $\begin{array}{l}\text { Unique } \\
\text { coverage }\end{array}$ & Consistency \\
\hline$\sim$ mianzi & 0.3774 & 0.0709 & 0.9562 \\
\hline $\begin{array}{l}\text { Self-presentation } \\
\text { attitude* } \\
\text { monitoring }\end{array}$ & 0.4899 & 0.1838 & 0.9203 \\
\hline Solution coverage: 0.5617 & Raw coverage & $\begin{array}{l}\text { Unique } \\
\text { coverage }\end{array}$ & Consistency \\
\hline Solution consistency: 0.9085 & 0.0727 & 0.9439 \\
\hline China & 0.7949 & 0.0624 & 0.9519 \\
\hline mianzi & 0.7898 & \\
\hline $\begin{array}{l}\text { Self-presentation } \\
\text { attitude }\end{array}$ & Solution coverage: 0.8623 &
\end{tabular}




\section{Compared analysis}

According to the value of hypothesis 2 is 3.67 from table 5 or figure 2, the difference between Korean and Chinese consumers towards luxury brand is significant (0.042 and 0.059), the Korean consumers demonstrate stronger impact on Self-monitoring towards Self-presentation attitude than Chinese consumers.

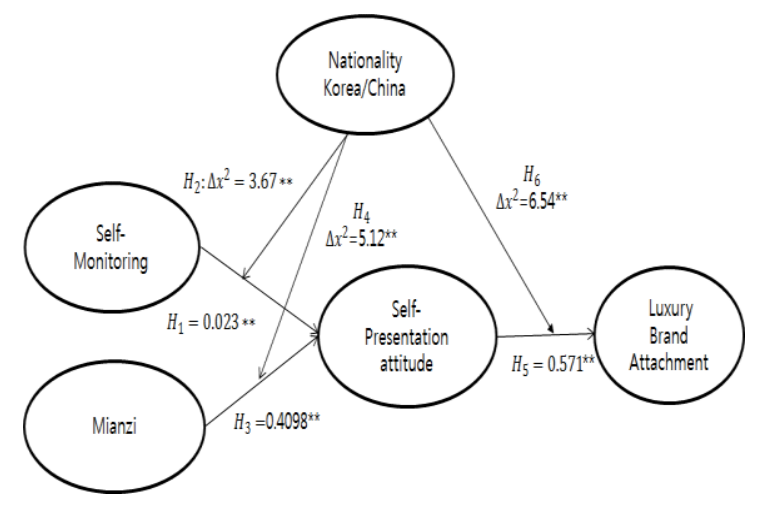

Fig. 2. Hypotheses Testing Results for Luxury Atta chments

This means that Korean consumers value their images in other's eyes more than Chinese consumers by purchasing luxuries. The hypothesis regarding Mianzi towards Self-presentation attitude is accepted, all of coefficients were positive and significant ( $\mathrm{H} 4$ : 0.5076 and 0.2811 , respectively, $\mathrm{p}<0.01$ ).

The difference between Chinese and Korean groups is significant (=5.12 and 4.99), supporting H4. With respect to Self-presentation attitude, Chinese consumers demonstrate stronger impact of sense of Mianzi than Korean customers.

This means Chinese consumers show their vanities more than Korean consumers by purchasing luxuries. According to the values of fsQCA in Table 6, the Korean consumers also demonstrate stronger impact on Self-monitoring towards Self-presentation attitude than Chinese consumers. The comparative effectiveness of Mianzi cannot be found in the fsQCA model.

The hypothesis regarding Self-presentation attitude towards the luxury brand attachments is accepted, both of coefficients are positive and significant in China or Korea group $(0.443$ and 0.783 , respectively, p 0.01). The difference between China and Korea group is significant (=6.54), supporting H6.

The impact of Self-presentation attitude with respect to luxury brand attachments in Korean customers is stronger than Chinese customers. This means that Korean consumers love their luxuries more than Chinese consumers.

The hypothesis regarding Mianzi towards the luxury brand attachments is accepted, the difference between China and Korea group is significant ( $=4.21)$, supporting H8. The impact of Mianzi in China is stronger than Korea with respect to luxury brand attachments. From the results of Table 8, the estimated value is also statistically significant.

We find that the impact of Self-presentation attitude with respect to luxury brand attachments in Korean customers is weaker than Chinese customers. This is different from estimated value in Table 5. Considering the economic development level, this point does not conform to the reality well. The different impact of self-monitoring is also not statistically significant on both Korea and China.

\section{CONCLUSIONS}

Generally, luxury brands marketers would like to highlight their products' high quality and dependability to serve their global market strategy, because more and more customers consider about the consistency between the brand image and their internal beliefs.

In this paper, A new insight is provided into analysis of Chinese and Korean luxury consumption by investigating how consumers' Self-monitoring, Mianzi and Self-presentation attitude relate to the luxury brand attachments, reflecting the difference between Chinese and Korean customers.

The finds support the function theory of customers' beliefs showing that Self-monitoring and Mianzi have positive effect on the Self-presentation attitude toward luxury brand. Further, Self-presentation attitude have a positive impact on luxury brand attachments.

This study expands previous research by examining the formation of the luxury brand attachment (a new variable-Mianzi, is used) and comparing luxury brand attachments formation across culture.

The findings show that the Chinese customers have much worse impact of Self-monitoring towards Selfpresentation attitude than Korean customers; the Chinese customers have much stronger impact of sense of Mianzi than Korea customers with respect to self-presentation attitude. However, Self-presentation attitude with respect to luxury brand attachments have stronger impacts on Korean customers than Chinese customers.

These findings maybe provide some valuable strategic implications for luxury brand retailers who expect to do business in both Korean and Chinese markets. Because of Mianzi, Chinese consumers may be more conspicuous consumption and keep a more harmonious relationship with others by attaching themselves to luxury brand. In China, the marketing strategy of vanity and showing the LOGO of luxuries maybe more efficient. 
But Korean consumers maybe more focus on the Self-presentation attitude. In Korea, the marketing strategy of brand loyalty and low-key luxury is more efficient. Luxury brand manufacturers need to take note of these differentiations between Chinese and Korean consumers to achieve their market objectives.

\section{REFERENCES}

[1] Latter, Phau \& Marchegiani, C. (2010). The roles of consumers need for uniqueness and status consumption in haute couture luxury brands, Journal of Global Fashion Marketing, 1, 206-214.

[2] Snyder, M., \& DeBono, K. G. (1985). Appeals to Image and Claims about Quality: Understanding the Psychology of Advertising, Journal of Personality and Social Psychology, 49, 586-597.

[3] Snyder, M. (1974). Self-monitoring of expressive behavior, Journal of Personality and Social Psychology, 30, 26-37.

[4] Lennox, R., \& Wolfe, R. (1984). Revision of the SelfMonitoring Scale, Journal of Personality And Social Psychology, 46, 49-64.

[5] Qin, B. (2010). Examining U. S. and Chinese Students Purchase Intention Formation for Luxury Brands, Graduate Faculty of Auburn University.

[6] Cheng, C. Y. (1986). The concept of face and its roots, Journal of Chinese Philosophy, 12, 329-348.

[7] Ho, D. Y. F. (1974). On the Concept of Face, the American Journal of Sociology, 81, 867-884.

[8] King, A. Y. C. (2006). Face, Shame and the Analysis of Behavior Patterns of the Chinese, Chinese Social Psychological Review, 2, 48-64.

[9] Tsang, K.K., \& Wang, Y. (2013). Ingratiation, renqing, mianzi and attraction: a guanxi perspective, Scientific Journal of Pure and Applied Sciences, 2(2), 95-105.

[10] Wilcox, K., Kim, H. M., \& Sen, S. (2009). Why do consumers buy counterfeit luxury brands?. Journal of marketing research, 46(2), 247-259.

[11] Fournier, S. (1998). Consumers and Their Brands: Developing Relationship Theory in Consumer Research, Journal of Consumer Research, 24, 343-353.

[12] Thomson, M., MacInnis, D. J., \& Park, C. W. (2005). The Ties That Bind: Measuring the Strength Of Consumers Emotional Attachments to Brands, Journal of Consumer Psychology (Lawrence Erlbaum Associates), 15, 77-91.

[13] Bruno, G. (2013). Modeling links between the decisionmaking process and luxury brand attachments: An international comparison, Journal of Global Scholars of Marketing Science, 23(4), 361-378.

[14] Dana. L. A., James, B.K., Jame, B.Y., \& Qi, M.CH. (2016). Understanding consumer motivations to interact on brand websites in the international marketplace: Evidence from the U.S., China, and South Korea, Journal of Business Research, 69, 5909-5916.

[15] Snyder, M. (1986). Public Appearances, Private Realities: The Psychology of Self-Monitoring, New York: Freeman.

[16] Snyder, M., Berscheid, E., \& Matwychuk, A. (1988). Orientations toward Personnel Selection: Differential Reliance on Appearance and Personality, Journal of Personality and Social Psychology, 54, 972-979.

[17] Alvin and Chan. ( 2006). The Chinese Concepts of Guanxi, Mianzi, Renqing and bao: Their Interrelationships and Implications for International Business, Brisbane, Qld, and Queensland University of Technology.

[18] Jinfeng, W. et, al. (2013). Factors related to consumer behavior on Luxury Goods Purchasing in China, University of the Thai Chamber of Commerce.
[19] Seung, H.C. (2015). The Effect of Face sensitivity on Consumer's choice of Luxury product's logo, JKCA.

[20] Leary, Mark, R., \& Kowalski, R. M. (1990). Impression Management: A Literature Review and Two Component Model, Psychological bulletin, 107 (1), 34-47.

[21] Katz, D. (1960). The Functional Approach to the Study of Attitudes, the Public Opinion Quarterly, 24(2), 163-204.

[22] Shavitt, S. (1989). Products, Personalities and Situations in Attitude Functions: Implications for Consumer Behavior, Advances in Consumer Research, 16, 300-305.

[23] Nueono, J.L., \& Quelch, J.A. (1998). The Mass Marketing of Luxury', Business Horizons, 1(6), 61-68.

[24] Malär, L., Krohmer, H., Hoyer, W. D., \& Nyffenegger, B. (2011). Emotional Brand Attachments And Brand Personality: The Relative Importance of the Actual and the Ideal Self, Journal of Marketing, 75, 35-52.

[25] Park, C. W., MacInnis, D. J., Priester, J., Eisingerich, A. B., \& Iacobucci, D. (2010). Brand Attachments and Brand Attitude Strength: Conceptual and Empirical Differentiation of Two Critical Brand Equity Drivers, Journal of Marketing, 74, 1-17.

[26] Park, C. W., \& MacInnis, D. J. (2006). What's In and What's Out: Questions on the Boundaries of the Attitude Construct, Journal of Consumer Research, 33, 16-18.

[27] Lippa, R. (1976). Expressive Control and the Leakage of Dispositional Introversion-Extraversion During Role-Played Teaching, Journal of Personality, 44, 541-559.

[28] Daphna, O., Heather M. C., \& Markus K. (2002). Rethinking Individualism and Collectivism: Evaluation of Theoretical Assumptions and Meta-Analyses, American Psychological Association, 128(1), 3-7.

[29] Simons, C. (2006). China's elite laps up luxury: Country's economic boom creates wealth and Demand for the finer things in life, Retrieved June 1, 2007, from EBSCO host database.

[30] Myung, S.C. (2009). The Effects of Social-face Sensitivity, Conspicuous consumption and Preference of Fashion Luxury goods on purchasing behavior of Fashion Counterfeits, the Research Journal of the Costume Culture, 17(2).

[31] Swaminathan, V., Karen, L.P., \& Gu, C. Z. (2007). My brand or our brand: the effects of brand relationship dimensions and self-construal on brand evaluations, Journal of Consumer Research, 34(2), 248-59.

[32] Hyejoo, L., \& Hojung, C. (2013). Individual Characteristics and Social Function attitudes on Luxury Brand Purchase intentions, the Korea Society of Clothing and Textiles, 37(7), 922-934.

[33] Grossman, G. M., \& Shapiro, C. (1988). Foreign Counterfeiting of status goods, Quarterly Journal of Economics, 103(1), 79-100.

[34] Cormrey, A. L. (1978). Common Methodological Problems in Factor Analytic Studies, Journal of Consulting and Clinical Psychology, 46(4), 648-659. 